\title{
Gamle - og pasienter med demens - Omsorg ved livets slutt
}

\author{
Stein Husebø ${ }^{1}$ og Bettina S. Husebø ${ }^{2}$ \\ 1) Verdighetsenteret - Omsorg for gamle, Ellerhusensvei 35, 5043 Bergen \\ 2) Universitetet i Bergen, Institutt for samfunnsmedisinske fag, Senter for alders- og sykehjemsmedisin \\ E-post: sthusebo@c2i.net
}

\begin{abstract}
SAMMENDRAG
I livets siste leveår vil det store flertall gamle og pasienter med demens trenge kompetent omsorg, pleie, vurdering og behandling, med respekt for deres livsprosjekt og verdighet. Alle vil i de siste måneder, uker, dager og timer før de dør trenge kompetent omsorg ved livets slutt (palliative care), uavhengig av diagnose eller oppholdssted - til alle døgnets tider. Artikkelen drøfter utfordringer og muligheter, grunnlaget for nødvendig kompetanse: etikk, forberedende samtaler, organisering og samhandling.
\end{abstract}

«En medisinsk revolusjon har forlenget livet til våre gamle, uten å sikre dem den verdighet og trygghet de fortjener i deres siste leveår.» (John F. Kennedy 1960). I de fleste i-land vil flertallet rekke en levealder langt over 80 år. I deres siste, sårbare leveår vil de i tiltagende grad bli avhengig av pleie og omsorg. Hvilke behov har de? Hvordan kan vi etablere en garanti for optimal trygghet og verdighet $i$ deres siste år før døden (1)? Denne artikkelen bygger på et usystematisk litteratursøk og egne erfaringer gjennom klinisk virksomhet i 32 år.

\section{VERDIGHET}

De fleste filosofer knytter verdighet til autonomi og selvbestemmelse. Forfatteren Max Frisch (1911-1991) uttrykker det slik: «Verdighet betyr frihet til å velge». Den store og økende andel av pasienter med demens vil i sine leveår $i$ tiltakende grad oppleve kognitiv svikt og tap av autonomi (2). Pasienter med alvorlig demens vil ofte være avhengig av at andre velger for dem. De har fortsatt sin iboende verdighet, men vil være avhengig av at andre hjelper til å treffe et godt valg, basert på god forståelse og kompetanse og gode holdninger $(2,3)$. En sentral forutsetning for respekt av gamle og personer med demens sin verdighet er grundig kjennskap til pasientens biografi, som også må inkludere pasientens samlede livsprosjekt: Hvilke mål og avgjørelser er viktig for pasienten i den tiden som er igjen av livet?

En sykepleiers uttalelse på et seminar med fokus på demens illustrerer hvor sårbar de gamles verdighet er: «Når jeg blir gammel, syk, ensom, avhengig av pleie og omsorg, er jeg takknemlig for å få komme på sykehjem... Men om noen prater over hodet mitt uten å forsøke å se meg, eller fjerner min BH uten å vurdere om jeg hadde ønsket å beholde den, håper jeg at jeg i stand til mord...»

Nora, 92 år, traff spikeren på hodet med sin kommentar: «De gir meg en pille så jeg skal slutte å gråte for mannen min døde...»

\section{ÅPEN, FORBEREDENDE KOMMUNIKASJON}

Den sentrale nøkkel til en optimal omsorg ved livets slutt, er åpen, forberedende kommunikasjon med pasient og pårørende, med fokus på de sentrale spørsmål: Om livet som nærmer seg slutten. Om medisinske og etiske utfordringer (4). Om trygghet og god omsorg natt og dag. Om en palliativ plan som sikrer lindring av plagsomme symptomer $(5,6)$. Om å forebygge unødige behandlinger og transporter i den tiden som er igjen. Om at sult eller tørst sjelden er en belastning for de døende, og at dryppet ikke er løsningen, men at utfordringen er munnhygiene og fukting av lepper, munn og svelg $(7,8)$. Om at døden er en befrielse for de døende. Om at alle spørsmål og reaksjoner er tillatt. Om hvor pasienten har det best i tiden som kommer. Om hvem som er ansvarlig for hva. Om forsoning og farvel.

Legen må ta rollen og initiativet til disse så avgjørende samtaler (9). Uten legen vil det ikke være mulig å drøfte de sentrale etiske og medisinskfaglige utfordringer. Mange leger finner det vanskelig å drøfte livsprognose. «Det vet vi aldri!» har vi hørt mange ganger fra kollegaer. Men hos multimorbide, sterkt pleietrengende gamle bør legen i god tid reflekterer over spørsmålet: «Tror vi at denne pasienten vil være i live om 6 måneder?» og drøfte spørsmålet med pleiepersonalet som har betydelig erfaring og kompetanse for å vurdere svaret (10). Dersom svaret er ja bør de pårørende innkalles til den gode, forberedende, åpne samtale, samtidig som det utarbeides, dokumenteres og gjøres tilgjengelig en palliativ plan om etikk, kontakt og symptomlindring (6).

Det store og økende antall pasienter med demens er her en spesiell utfordring. De mister i sine siste leveår i tiltagende grad kognitiv evne. Derfor bør samtalene om disse viktige spørsmål finne sted mens de ennå er i stand til å forstå og velge.

\section{ER DET HÅP - DOKTOR?}

Legenes håp har ofte hovedfokus på overlevelse. Kommentarer som: «Min oppgave som lege er å utsette og 
bekjempe døden med alle midler, og støtte pasientens håp,» er vanlig $(11,12)$.

Helsevesenet har som hovedmål å bekjempe sykdom og diagnoser og bidra til et godt, langt liv, en målsetting de deler med pasienter og pårørende. Men før eller senere, spesielt i forhold til de multimorbide, sterkt pleietrengende gamle, blir dette håpet for oss alle urealistisk. Vi må skifte fot. Det betyr på ingen måte at det ikke lenger er håp. Tvert i mot. Det er kanskje mer håp enn noensinne. Men håpene har endret karakter og innhold.

Om vi da later som at alt er som før, med dødsforakt behandler alle livstruende komplikasjoner, og unnlater de nødvendige initiativ til åpne, forberedende samtaler, som i Ibsens «Vildanden» (13) eller Tolstojs «Ivan Iljitsch død» (14), fratar vi pasient og pårørende håp.

Med åpenhet er døende pasienters håp grandiose. Håp om åpenhet, sosiale relasjoner, om å elske, om å bli elsket, om tro, tvil, mening, forsoning, forberedende sorg, holdning og farvel.

Den største krenkelse av verdighet og håp vi kan forestille oss, er at døden fant sted bortgjemt bak et skjermbrett på institusjon, eller få timer etter unødig og belastende transport mellom hjemmet, sykehjem eller sykehus.

\section{PASIENTER MED KOGNITIV SVIKT - FORMODET SAMTYKKE}

Telefonen ringte søndag kveld. Sykepleieren sa: «Kona er hos Oddvar. Hun sier at han har lungebetennelse.» Oddvar var 83 år og pasient på sykehjemmets demensavdeling. De siste månedene hadde han vært bundet til sengen. På grunn av hans langt utviklete kognitive svikt, var nå kommunikasjon ikke lenger mulig. Men hans kone Nina kom trofast hver dag og satt lenge hos ham.

Jeg kjørte til sykehjemmet og undersøkte Oddvar. Så gikk vi på vaktrommet og satte oss ned, Nina, sykepleieren og jeg. «Han har lungebetennelse, ikke sant doktor?....» sa Nina. «Du er en god doktor,» svarte jeg. «Da gir vi vel penicillin?» spurte hun. «Vel,» svarer jeg etter en liten pause: «Å gi penicillin er den ene siden. Jeg har et viktig spørsmål til deg. Hva hadde Oddvar villet i denne situasjonen?» «Han var en stolt mann... Oddvar hadde villet at det var slutt for lenge siden...» «Det er den andre siden,» svarte jeg. Etter en pause fortsatte hun: «Men er det ikke fælt å dø av lungebetennelse?» «Tidligere kalte vi lungebetennelse den gamles venn. Og vi kan lindre plagene som han måtte ha...» «Da gir vi ikke penicillin... Men, du må vite at jeg er veldig glad i han... Oddvar fikk god palliative care og ikke penicillin. Han døde fredfullt 4 dager senere med Nina, barn og barnebarn til stede.

Svaret på vårt spørsmål til Nina: «Hva hadde Oddvar villet i denne situasjonen?» gir informasjon om hans formodete samtykke, hvor Nina tydelig bekrefter at han ville sett på døden som en befrielse. Hadde vi spurt: «Hva ønsker du i denne situasjonen?» ville svaret kanskje vært annerledes. Nina er glad i Oddvar, og ikke helt forberedt på at han nå vil dø. Mange pårørende til døende pasienter vil slite med «å slippe» den de er glad i og kan trenge tid og noen som lytter.

De fleste gamle vil på slutten av sine liv rekke et punkt hvor døden ikke lenger er den store fiende, men hvor de ser frem til og aksepterer at livet og plagene tar slutt (14). Mange vil ha kognitiv svikt med bakgrunn i sykdommer eller demens, og ha mistet sin evne til å forstå og treffe beslutninger. Informert samtykke vil da ikke lenger være mulig. Det er da formodet samtykke som den etiske ledesnor (15-17). Samtidig kan også pasienter med demens lenge gi uttrykk for mangt, og deres stemme må høres (18).

Det store flertall av de gamle er tydelige på dette punkt: «Når jeg er sterkt pleietrengende og bundet til sengen, ikke lenger kontaktbar, når mine plager dominerer over min livskvalitet: Hold meg ikke i live med livsforlengende tiltak, men la meg dø i fred.»

I slike situasjoner kan vår diagnose-orienterte medisinske grunnholdning bli en trussel for pasientens verdighet. Døende pasienter dør som følge av diagnoser og deres komplikasjoner. Før eller senere skal vi ikke lenger bekjempe disse komplikasjoner. Det er ikke lenger indikasjon for kunstig ernæring eller intravenøs væsketilførsel. Hjertesvikt, nyresvikt eller pneumoni blir til pasientens mulighet til en fredfull død. Alle livsforlengende eller unødige medikamenter bør seponeres. Den terapeutiske oppgaven skifter til optimal palliative care og signalet til pasient og pårørende: «Vi respekterer pasientens liv, så lenge han lever.»

\section{HVEM TREFFER BEHANDLINGSAVGJØ- RELSER? - INFORMERT SAMTYKKE}

Som ansvarlig anestesilege møtte jeg Liv, 84 år til preoperativ samtale. 8 måneder tidligere ble hun operert for kreft i tykktarmen. Hun utviklet omfattende metastaser i buken, og hadde nå fistler fra tarmen til skjeden og urinveiene. Fra disse stedene lekket det tyntflytende avføring. Hun stod på operasjonsprogrammet neste dag.

Hennes allmenntilstand var svært svak. Jeg tvilte sterkt på om hun ville overleve et slikt inngrep og oppsøkte kirurgen som skulle operere. «Hvor stor er sjansen for at inngrepet lykkes?» spurte jeg. «Det er betydelig risiko for komplikasjoner,» svarte han, «men vi har ikke noe valg. Hun har det forferdelig slik det nå har utviklet seg.» «Tror du hun kommer levende ut av intensivavdelingen?» spurte jeg. «Du er intensivspesialist, hva tenker $d u$ ?» «Sannsynligheten for postoperative komplikasjoner og infeksjoner er overveldende,» svarte jeg. Hun vil sannsynligvis dø på respirator.» «Men vi har ikke noe valg...» sa han.

Så diskuterte vi det sentrale spørsmål: Hvem har valg... Som følge av vår samtale oppsøkte vi henne, og diskuterte situasjonen med den samme åpenhet som 
i vår diskusjon. Hun lyttet, stilte noen spørsmål, før hun sa: «Om jeg har forstått dere to riktig, har jeg valget mellom en svært risikofylt operasjon eller å reise hjem. Uansett hva jeg velger, har jeg kort tid igjen før jeg dør, noen uker eller kanskje en måned... Er det riktig?» Da vi bekreftet fortsatte hun: «Tusen takk for at dere er så åpne med meg... Jeg vil hjem...»

Hjemme fikk hun utmerket pleie og omsorg og palliative care. Hun døde hjemme i stuen fredfullt 4 uker senere, omgitt av sine nærmeste.

Helsepersonell er pålagt å innhente informert samtykke før alle former for diagnostiske og terapeutiske intervensjoner, spesielt når risiko og komplikasjoner kan være omfattende eller livstruende. Vi må tegne veikartet sammen med dem, på en måte de forstår, og diskutere åpent risiko, nytte, fordeler og ulemper ved de ulike valg. Er livsprognosen sterkt begrenset, må vi snakke åpent om det. Vi må ikke holde tilbake eller «pynte på» vital informasjon. Vi må lytte til bekymringer og spørsmål, og være beredt til å gi dem råd basert på vår kompetanse og erfaringer i slike situasjoner. Etter slike åpne samtaler bør vi stille kontrollspørsmål: «Kan dere gjenta hovedtrekkene i vår samtale?» Vi vil da ofte erfare at pasienter og pårørende ikke helt har forstått hva vi har formidlet og at det er behov for gjentagelse og flere samtaler. Vi vil også oppdage at de fleste mennesker har mer mot og kurasje enn vi forestiller oss.

Før den andre, åpne samtalen med Liv, var disse forutsetninger ikke oppfylt. Hennes informerte samtykke var ikke informert, det var basert på halve sannheter og halv åpenhet. Hun trengte at vi direkte snakket om den sterkt begrensede livsprognose før hun kunne gi oss sitt endelige informerte samtykke, en avgjørelse om å dra hjem, radikalt ulikt å gjennomgå en svært belastende operasjon i sin siste levetid.

\section{Plan for Palliative Care}

Åpen, forberedende kommunikasjon, kompetent vurdering av etikk og planlegging og etablering av palliative care kan sikre den nødvendige trygghet og kvalitet for behandling, pleie og omsorg for gamle i deres siste livsfase. Forberedende planlegging vil muliggjøre at flere gamle pasienter kan leve og dø i sine hjem eller på sykehjem, og forhindre krenkende transporter og overføringer i de siste dagene før de dør (19).

Den palliative plan må inneholde nødvendig informasjon om diagnoser, kommunikasjon og etikk, for eksempel: «NN lider av fremskritt demens med kognitiv svikt. Hun har hatt flere tilfeller med hjertesvikt. Situasjonen er grundig drøftet gjentatte ganger med familien. Det er enighet om at hun ved livstruende komplikasjoner ikke skal innlegges på sykehus eller få livsforlengende behandling, men få være her med optimal palliasjon.»

Den palliative plan må også inneholde forslag til behandling av eksisterende eller sannsynlige plagsomme symptomer, som smerte, dyspne, angst, panikk, dødsralling med mer, og det må sikres at de nødvendige medikamenter er lett tilgjengelig når behovet oppstår (7).

Ved smerte eller dyspne: Morfin 5-10 mg subkutant hver 4. time.

De fleste pasienter dør som følge av akutt hjertesvikt. Flertallet av disse pasientene vil oppleve en kvelende fornemmelse av dyspne. Det eneste tiltaket som gir rask og effektiv lindring er tilførsel av morfin.

Dødsralling - en støyende og belastende respirasjon med bakgrunn i slimopphoping i de store luftveier, vil opptre hos mer enn $50 \%$ av de døende (20). Antikolinergika som scopolamin 0.3-0.6 mg subkutant vil lindre effektivt hos de fleste.

Panikk, angst eller uro - kan lindres effektivt med midazolam 2.5-5 mg subkutant. (Midazolam er i motsetning til andre benzodiazepiner vannløselig, hvilket gir en rask og sikker effekt ved subkutan administrasjon.)

I de siste ukene og dagene av pasientens liv, når pasienten oppholder seg hjemme eller på sykehjem, bør legene gi anledning til at pårørende eller pleiepersonalet kan ta direkte kontakt per telefon døgnet rundt. Dette vil gi et betydelig bidrag til trygghet og forhindre unødige sykehusinnleggelser av døende pasienter (21).

Den skriftlige, kortfattede palliative planen som tar stilling til og dokumenterer tiltakene som er nevnt her, bør være lett tilgjengelig for alle aktuelle aktører dersom eller når det oppstår nødsituasjoner.

I en verdifull lederartikkel i BMJ med overskriften: «Hvorfor gir legene livsforlengende behandling til døende pasienter?» fokuserer Doust på sentrale utfordringer for en optimal omsorg for gamle $\mathrm{i}$ deres siste livsfase (22). Hun starter med: «Ikke bare stå der! Gjør noe!» - hvilket gjenspeiler holdningen vi lærer i legeutdanningen. Hun konkluderer etter grundige drøftinger med det motsatte: «Ikke bare gjør noe! Sitt ned!»

Hvordan en person dør forblir i erindringene til familien - som hindringer eller ødeleggelse av sorgen som følger, eller lindrende, som et høydepunkt av verdighet og omsorgsfullt farvel (23).

Om vi i den siste tiden av pasientens liv lykkes med åpen, forberedende kommunikasjon, god og kompetent etikk med respekt for informert eller formodet samtykke, lindring av plagsomme symptomer vil vi ofte oppleve den optimale tilbakemelding fra de pårørende etter dødsfallet: «Vi kunne ikke forestille oss å miste mor. Vi var fylt med angst og fornektelse. Men disse siste ukene og dagene av hennes liv, har vært et høydepunkt for oss alle...» 


\section{REFERANSER}

1. Lothian K, Philp I. Care of older people - Maintaining the dignity and autonomy of older people in the healthcare setting. BMJ 2001; 322 (7287): 668-670.

2. Westius A, Kallenberg K, Norberg A. Views of life and sense of identity in people with Alzheimer's disease. Age Soc 2010; 30: 1257-1278.

3. Johannessen A, Haugen P, Moller A. Persons with early onset dementia - experiences of living with dementia: A qualitative study. Int Psychgeriatr 2011; 23: S209-S210.

4. Dening KH, Jones L, Sampson EL. Advance care planning for people with dementia: a review. Int Psychgeriatr 2011; 23 (10): 1535-1551.

5. Ellershaw J. Care of the dying: what a difference an LCP makes! Pall Med 2007; 21 (5): 365-368.

6. Husebo SB, Husebo BS. Eldreomsorg - Palliativ Plan. Nord Tidsskr Pall Med 2011; 28 (2): 43-50.

7. Husebo BS, Husebo SB. [Nursing homes as arenas of terminal care - how do we do in practice?]. Tidsskr Nor Laegeforen 2005; 125 (10): 1352-1354.

8. Palecek EJ, Teno JM, Casarett DJ, Hanson LC, Rhodes RL, Mitchell SL. Comfort feeding only: a proposal to bring clarity to decision-making regarding difficulty with eating for persons with advanced dementia. $J A m$ Geriatr Soc 2010; 58 (3): 580-584.

9. Husebo BS, Husebo SB. Behandling i livets slutt - legen har nøkkelposisjon. Tidsskr Nor Laegeforen 2012; 12 (13): 1426-1427.

10. Lynn J. Serving patients who may die soon and their families - The role of hospice and other services. JAMA 2001; 285 (7): 925-932.

11. Hertogh CMPM. Advance care planning and the relevance of a palliative care approach in dementia. Age Ageing 2006; 35 (6): 553-555.

12. Husebo SB. Is there hope, doctor? J Pall Care 1998; 14: 43-8.

13. Ibsen H. Vildanden. Samlede Verker, Bind 2. Oslo: Kagge Forlag, 2002.

14. Tolstoy Leo. The Death of Ivan Ilych. Penguin Red Classic edition 2006: 1886.

15. Bravo G, Dubois MF, Paquet M. Advance directives for health care and research - Prevalence and correlates. Alzheimer Disease Assoc Dis 2003; 17: 215-222.

16. Derse AR. Making decisions about life-sustaining medical treatment in patients with dementia. Theoret Med Bioethics 1999; 20: 55-67.

17. Margiotta A, Iacono S, D'Autilia N, Luberto S, Pinelli M, Baldelli MV, et al. Diagnostic, therapeutic, ethic and legal issues in caring for dementia: The viewpoint of medical representative in Modena (Italy). Arch Gerontol Geriatr 2002; 11: 191-198.

18. Allen RS, DeLaine SR, Chaplin WF, Marson DC, Bourgeois MS, Dijkstra K, et al. Advance care planning in nursing homes: Correlates of capacity and possession of advance directives. Gerontologist 2003; 43 (3): 309 317.

19. Graverholt B, Riise T, Jamtvedt G, Ranhoff AH, Kruger K, Nortvedt MW. Acute hospital admissions among nursing home residents: a population-based observational study. BMC Health Serv Res 2011; 11: 15-21.

20. Hughes AC, Wilcock A, Corcoran R. Management of "death rattle". J Pain Sympt Manage 1996; 12 (5): 271 272.

21. Bollig G, Husebo BS, Husebo SB. Vakttjenester for leger på sykehjem. Tidsskr Nor Laegeforen 2008; 23: 2722-2724.

22. Doust J, Del Mar C. Why do doctors use treatments that do not work? For many reasons - including their inability to stand idle and do nothing. BMJ 2004; 328 (7438): 474-475.

23. Saunders C. Pain and impending death. Textbook of Pain. London: Churchill Livingstone, 1994. 